\title{
DIREITO, CIÊNCIA DO SOCIAL: O LUGAR DOS JURISTAS NOS DEBATES DO BRASIL DOS ANOS 1930 E 1940
}

Law, science of the social: the place of jurists in the debates of Brazil in the 1930's and 1940's

MARIANA DE MORAES SILVEIRA

http://dx.doi.org/10.1590/S2178-14942016000200007

Mariana de Moraes Silveira é mestre em História e Culturas Políticas pela Universidade Federal de Minas Gerais (2013) e doutoranda em História Social pela Universidade de São Paulo (início em 2014) (marianamsilveira@gmail.com).

Artigo recebido em 29 de abril e aprovado para publicação em 15 de junho de 2016. 


\title{
RESUMO
}

Este artigo analisa o lugar dos juristas nos debates do Brasil dos anos 1930 e 1940. A partir do estudo das revistas Forense e Cultura Política, argumentamos que aproximações em torno de temas como a hostilidade ao parlamento, a busca por um conhecimento objetivo da sociedade, projetos de reformas legislativas e a chamada "socialização do direito" permitiram que o governo Vargas e os bacharéis em direito tecessem laços bastante estreitos. No início da década de 1940, entretanto, essas relações se tornaram mais tensas, e muitos juristas passaram a endossar a oposição liberal ao Estado Novo.

PalaVras-CHAVE: intelectuais; direito; revistas; governo Vargas.

\begin{abstract}
This article analyzes the place of jurists in the debates in Brazil during the 1930's and 1940's. Through a study of the magazines Forense and Cultura Politica, we sustain that proximities around topics such as the hostility to parliament, the search for an objective knowledge of society, projects of legislative reforms and the so-called "socialization of law" made it possible for the Vargas government to develop close ties with law graduates. In the early 1940's, however, these relations grew strained, and several lawyers adhered to the liberal opposition to the Estado Novo dictatorship.
\end{abstract}

KeYwords: intellectuals; law; magazines; Vargas government.

\section{RÉSUMÉ}

Cet article analyse la place des juristes dans les débats tenus au Brésil aux années 1930 et 1940. À partir de l'étude des revues Forense et Cultura Política, nous soutenons que des proximités autour de thèmes tels que I'hostilité au parlement, la quête d'une connaissance objective de la société, les projets de réforme législative et la "socialisation du droit" ont permis le développement de liens assez étroits entre le gouvernement Vargas et les gradués en droit. Vers 1940, cependant, ces relations sont devenues plus tendues, et beaucoup de juristes ont commencé à appuyer l'opposition libérale à la dictature de l'Estado Novo.

Mots-CLÉs: intellectuels; droit; revues; gouvernement Vargas. 


\section{UMA HISTÓRIA INTELECTUAL DO DIREITO NO GOVERNO VARGAS}

E m julho de 1936, Francisco Campos discursou em um almoço oferecido aos participantes de um encontro acadêmico promovido com o intuito de debater as reformas das leis processuais que se projetavam. 0 então secretário de Educação e Cultura do Distrito Federal abriu sua fala saudando o congresso como "um dos mais auspiciosos acontecimentos no quadro das atividades construtivas e renovadoras com que o Brasil vem procurando [...] corresponder às novas exigências da época de transformações sociais, econômicas, jurídicas e políticas". Ele sugeriu que o ensino do direito deveria ser reformado, passando "do plano da memorização e dos dogmas para o da investigação e da crítica, para o que seria imprescindível estender o campo dos estudos jurídicos a outros domínios de fato". Destacou, ainda, a necessidade de que "a experiência dos juristas seja inteligentemente utilizada tanto na ordem crítica, como nas atividades construtivas ou criadoras do direito" (Congresso, 1936: 809-810).

Campos teria a oportunidade de traduzir algumas dessas propostas em medidas práticas durante o período em que esteve à frente do Ministério da Justiça (1937-1941), quando diversas reformas legislativas havia muito cogitadas se concretizaram. A espécie de refundação do direito nacional que o governo Vargas buscara iniciar já em 1930 foi, em média, bem recebida entre os bacharéis em direito. 0 sucesso dessa articulação entre governo e juristas deve ser entendido à luz do fato de que os intuitos de fazer do direito uma ciência do social e de garantir que o saber "técnico" fosse empregado na escrita das leis estiveram longe de ser um projeto isolado de Campos.

Desde a virada do século XIX ao XX, seus colegas de formação das mais variadas latitudes e orientações políticas vinham buscando novos rumos para a disciplina e reivindicando modos de inserção na vida pública que não se resumissem à ocupação de cargos parlamentares ou burocráticos. Sob o impacto de processos como a industrialização e o acelerado crescimento das cidades e das inquietações com o que se chamou de "questão social", estreitamente ligada ao fortalecimento das lutas operárias, as concepções jurídicas que haviam prevalecido ao longo do oitocentos foram denunciadas como excessivamente individualistas, abstratas e centradas nos textos legais. Difundiu-se, assim, uma preocupação em promover a "socialização do direito", fazendo das normas jurídicas instrumentos de reforma social. Para 
tanto, seria essencial promover uma aproximação do direito com a nascente sociologia e garantir que estudos rigorosos informassem a feitura das leis (Audren, 2011: 7-33; Kennedy, 2006: 19-73).

Essas reivindicações encontraram um terreno fértil para desabrochar no Brasil dos anos 1930 e 1940. Desde, ao menos, a década de 1910, intelectuais de diversas vertentes se propuseram a conhecer a "realidade nacional" a partir de bases tidas como objetivas, em busca de caminhos para superar o "atraso" brasileiro e atribuindo a si próprios um papel crucial na condução dos rumos do país (Bresciani, 2007; Dutra, 2005). Em boa medida, eles conquistariam esse lugar ao longo dos anos em que Getúlio Vargas permaneceu no poder, sobretudo por meio das atividades desenvolvidas ao redor do Ministério da Educação (Bomeny, 2001; Gomes, 1996).

Ganharam força, a partir da criação dessa pasta, a estruturação das universidades e a institucionalização das ciências sociais, em conexão com os esforços para dotar o Estado de quadros especializados, tidos como "técnicos" e aptos a conduzir à modernização (Dutra, 2005: 182; Gomes, 1994: 5; Santos, 2002: 24-25). Os cursos de humanidades surgiram no Brasil, assim, sob a dupla pretensão de alcançar um conhecimento objetivo acerca da sociedade e de formar assessores estatais.

Esses processos foram perpassados pelas tensões políticas do período. Em 1933, fundou-se a Escola Livre de Sociologia e Política, incorporada à Universidade de São Paulo no ano seguinte. No Rio de Janeiro, a Universidade do Distrito Federal (UDF), de orientação progressista e laica, passou a oferecer cursos como os de história e sociologia em 1935. Em articulação com a Igreja, o governo Vargas promoveu medidas de repressão à UDF, e sua extinção se viabilizou após o golpe do Estado Novo. Em julho de 1937, havia-se fundado a Universidade do Brasil (UB), cuja Faculdade Nacional de Filosofia foi criada em 1939, incorporando parte dos quadros da UDF (Ferreira, 2012: 613-614; Oliveira, 1995: 237-249).

A crítica ao "bacharelismo", entendido como um conhecimento retórico e avesso aos procedimentos científicos, foi uma via frequentemente adotada pelos discursos de legitimação desses novos domínios do saber (Coelho, 1999: 272-275; Mattos, 2011: 16-18). 0 que muitas vezes se ignora, entretanto, é que, longe de permanecerem inertes em face de tais censuras, os juristas procuraram reformar suas práticas e teorias. Fizeram-no em diálogo com movimentos internos à disciplina, mas também com os debates mais ampliados do período.

Não se pode esquecer, por outro lado, que os graduados em direito haviam atuado como polígrafos, empregando suas penas não apenas em reflexões sobre o universo jurídico, mas também em análises sobre a sociedade, na literatura e na estruturação política do país 
(Adorno, 1988; Oliveira, 1995: 235-237). Em 1879, as formações disponibilizadas pelas faculdades de direito foram divididas em "ciências jurídicas" e "ciências sociais", em um movimento que se ligou mais à abertura de distintos caminhos profissionais que a transformações acadêmicas efetivas (Venancio Filho, 2004: 84). Foi somente por volta da década de 1930 que a defesa da necessidade de estudar o social ganhou os contornos de um projeto de reformulação do saber jurídico.

Este artigo tem como objetivo analisar o lugar dos juristas nos debates do Brasil dos anos 1930 e 1940, dando destaque à busca por fazer do direito uma ciência do social. Argumentamos que, a despeito da narrativa segundo a qual 1930 representa um marco do declínio da atuação política dos bacharéis em direito no Brasil,, ${ }^{1}$ tais homens seguiram tendo um acesso privilegiado ao aparato estatal e ocuparam um lugar relevante no governo Vargas. Buscamos, igualmente, trazer à tona a complexidade dos laços entre juristas e Estado, mostrando que não se sustenta o "mito da resistência generalizada" à ditadura varguista que órgãos como 0 Instituto dos Advogados Brasileiros (IAB) e a Ordem dos Advogados do Brasil (OAB) buscaram construir em suas memórias institucionais (Mattos, 2011: 64-69).

Analisamos o direito no âmbito da história intelectual, ${ }^{2}$ em um diálogo entre "a história política, a história das elites culturais e a análise histórica da 'literatura de ideias'" (Altamirano, 2005: 14). Audren (2015: 1-4) propôs que o estudo das "práticas intelectuais a partir das quais o direito é produzido, mobilizado ou ainda aplicado" pode constituir uma via frutífera para colocar em diálogo a "história jurídica" e a "sócio-história". A atenção a mecanismos como escrita de textos, realização de congressos, organização de instituições representativas permitiria compreender como o direito se legitima e atua socialmente, sem reduzi-lo a mero reflexo de relações de outra natureza, nem analisá-lo puramente em sua lógica interna ou respaldar discursos ideologizados sobre sua autonomia e sua neutralidade.

Seguindo a proposta de Grafton (2006: 27-30) sobre como o estudo dos impressos pode constituir uma "base material" da história intelectual e entendendo o ato editorial como uma forma de intervenção política, escolhemos como fontes centrais duas publicações periódicas. Fundada em Belo Horizonte em 1904, a Revista Forense consolidou-se como o principal mensário jurídico brasileiro a partir de sua transferência para o Rio de Janeiro, em 1936, capitaneada por Bilac Pinto e Pedro Aleixo, que se engajariam na derrubada de Vargas e integrariam os quadros da União Democrática Nacional (UDN). Cultura Política, por sua vez, foi lançada pelo Departamento de Imprensa e Propaganda (DIP) em março de 1941, com direção a cargo de Almir de Andrade, um dos principais ideólogos do Estado autoritário e professor da Faculdade Nacional de Direito (FND), instituição incorporada à UB em 1937 e frequentemente mobilizada em atividades de legitimação do regime. 
A análise desses periódicos nos permitirá mostrar trânsitos entre juristas e governo. Primeiramente, traçamos um panorama das questões jurídicas abordadas no periódico do DIP, para em seguida nos concentrarmos em um dos principais temas que aproximaram os bacharéis em direito dos projetos do varguismo: 0 antiparlamentarismo. Após uma discussão de como a busca por fazer do direito uma "ciência experimental" apareceu como uma possível solução para a suposta falência do Legislativo, examinamos os significados políticos desses debates, explicitando suas articulações com as críticas ao liberalismo. Para concluir, estabelecemos um balanço das relações entre juristas e política durante o governo Vargas, a partir do deslocamento que se observa em meados dos anos 1940.

\section{Direito E JURistas EM CUltura POlítica}

$\mathrm{E}$ ncontram-se nas páginas de Cultura Política inúmeros sinais da inserção dos juristas nos debates do período. A revista do DIP constituiu "um dos exemplos mais acabados da proposta política do Estado Novo", tendo "por objetivo esclarecer e divulgar para o grande público as transformações que o país sofria por obra das iniciativas governamentais" (Gomes, 2005: 190). 0 periódico é um observatório, também, da capacidade do regime de estabelecer relações com intelectuais de variados matizes: Nélson Werneck Sodré, Gilberto Freyre e Graciliano Ramos estavam entre seus colaboradores. De toda forma, não há dúvidas de que "as coordenadas do discurso" eram ditadas por indivíduos que ou estavam diretamente vinculados ao aparelho de Estado, ou tinham participação efetiva na montagem de seu projeto ideológico (Velloso, 1982: 78-79).

Cultura Política foi rápida e favoravelmente recepcionada entre os juristas. A Revista Forense noticiou seu lançamento já em março de 1941, citando o intuito, expresso no artigo de apresentação, de fazer da "revista mensal de estudos brasileiros" um "espelho do Brasil". Fez-se, também, um elogio aos colaboradores do periódico, descritos como "nomes da mais justa evidência nas ciências, na literatura, na política, etc." (Lima, 1941: 500). A Forense chegou a republicar, com menção da fonte, um artigo originalmente veiculado em Cultura Política (Carvalho, 1941: 70-89; Carvalho, 1942: 305-314).

0 interesse que esses comentários denotam encontra respaldo no conteúdo da publicação. Para além da presença de autores que frequentavam as páginas da imprensa especializada em direito, havia seções de Cultura Política voltadas para a análise de temas jurídicos. "A estrutura jurídico-política do Brasil" e "Legislação" constituíam divisões recorrentes da revista. Em alguns de seus primeiros números, o periódico publicou a série de artigos "Transformações no campo do direito", em que Luiz Antonio da Costa Carvalho, 
professor da FND, compunha "uma recapitulação histórica [...] da atividade legislativa do Governo" (A atividade..., 1941: 209).

Na abertura de um de seus fascículos, Cultura Política transcreveu o discurso de Getúlio Vargas como paraninfo dos formandos de 1941 da FND. Em diálogo tanto com a tradição do "bacharelismo" quanto com a busca por dotar o Estado de quadros "técnicos", Vargas sustentou que o ingresso na vida profissional ali selado deveria ser uma entrada também para a vida pública:

o direito não pode desaparecer, nem perderá jamais o seu valor ético, porque é um elemento indispensável à vida dos povos civilizados; acompanha-lhes, isso sim, o processo evolutivo, renovando os seus fundamentos e normas para melhor assegurar o equilíbrio social e a disciplina das relações humanas, como uma das suas condições existenciais. [...] 0 bacharel não é um mal brasileiro porque não é um mal. [...] 0 vasto hinterland precisa de elementos ativos da cultura e os reclama. Eles são úteis e impulsionam o progresso local. [...] 0 bacharel [...] é um agente de cultura no seu meio, porque mais afeito ao trato das ideias gerais e mais apto a compreender a sua terra e a sua gente sob um critério amplo e progressista (Vargas, 1942: 9-10).

Vargas deixou claro, assim, que reservara um lugar para os bacharéis em direito em seu governo, condizente com o papel que atribuiria aos intelectuais. Era praticamente um consenso, nesses anos, que tais homens, por serem "os que melhor captavam e expressavam" uma "consciência coletiva mais profunda", seriam atores essenciais para promover as reformas sociais necessárias para fazer com que nascesse um "Brasil moderno". Também o Estado, sobretudo na doutrina oficial varguista, foi visto como um elemento essencial da equação. Sendo a "correspondência com o 'espírito nacional'" o maior ideal a ser alcançado, o "próprio curso da política precisava ser orientado por 'profissionais' detentores de capacidades raras e definidas como 'hábito de pensar': os intelectuais" (Gomes, 1996: 137).

Esse projeto encontrou ampla ressonância nos meios acadêmicos brasileiros, em que já se vinha, nas décadas anteriores, traçando diagnósticos sobre a importância do conhecimento da "realidade nacional" como forma de encontrar caminhos para a superação do "atraso", diante de um povo visto como inculto e incapaz do autogoverno (Dutra, 2005: 232; Luca, 1999: 297-298). Os "homens do pensamento" atribuíam a si próprios, assim, um lugar de "consciência privilegiada do nacional", julgando-se legitimados a assumir "o papel de guia, condutor e arauto" (Velloso, 2011: 147).

A reivindicação de um papel de protagonismo na vida pública e as aproximações em torno a uma série de temas expõem as insuficiências das explicações dos laços entre o varguismo e os intelectuais fundadas na "cooptação" pela oferta do cargo público, em um mercado 
de trabalho restrito e de profissionalização incipiente, cuja formulação clássica se encontra no trabalho de Miceli (1979). As gerações atuantes entre as décadas de 1920 e 1940 não solicitaram "a mão protetora do Estado", mas sim se mostraram dispostas "a auxiliá-lo na construção da sociedade", em bases tidas como racionais (Pécaut, 1990: 22).

Discutindo o caso de Oliveira Vianna, Bresciani (2007: 483-484) mostrou que a atuação do jurista fluminense junto ao governo se ligou antes a um projeto intelectual e político por ele partilhado, em que o poder central e as elites desempenhavam papel de protagonismo. 0 antiliberalismo, em especial, não foi uma inclinação exclusiva de "políticos de tendências centralizadoras e autoritárias", mas sim "um lugar onde muitos se encontravam" (Bresciani, 2007: 298). Setores significativos da intelectualidade brasileira estavam de acordo com ao menos parte das medidas implantadas no pós-1930, já que as haviam construído discursivamente nos anos anteriores. Mais que "cooptação", houve uma convergência de interesses e de projetos. Em meio aos juristas, talvez nada o demonstre mais claramente que os ataques à política parlamentar.

\section{TEMAS DE UMA CONFLUÊNCIA: O ANTIPARLAMENTARISMO}

$\mathrm{E}$ m sua edição de outubro de 1941, Cultura Política trouxe uma contribuiç̧ão de Oscar Tenório, ${ }^{3}$ juiz no Distrito Federal. Com o título "A elaboração das leis no Estado Moderno", o trabalho tinha o claro objetivo de apregoar a falência do Legislativo e sustentar a necessidade do fortalecimento dos poderes presidenciais. Para Tenório, deslocar a competência do parlamento representaria uma "melhoria na técnica de legislar", indispensável diante das transformaç̧ões sociais que haviam trazido à tona a "necessidade de muitas leis, para regular matérias e resolver problemas até então deixados à voracidade do individualismo". Diante da "complexidade técnica das medidas legislativas da hora presente", apenas o Executivo disporia "de quadros de especialistas aptos à elaboração de textos seguros" (Tenório, 1941: 101-102).

Argumentos semelhantes se vinham construindo em outros âmbitos. A hostilidade ao Legislativo era um tema recorrente em meio aos os adeptos do positivismo. No Rio Grande do Sul da Primeira República, tal ideário foi chamado para "legitimar a rejeição aos sistemas representativos e o horror ao parlamentarismo" (Pécaut, 1990: 60-61). Na primeira constituição gaúcha sob o novo regime, o direito de elaborar as leis foi concedido prioritariamente ao presidente do estado, ficando as tarefas parlamentares praticamente reduzidas à fiscalização das contas públicas (Fonseca, 2012: 38-40). Estrutura semelhante foi prevista na Constituição de 1937, embora ela nunca tenha vindo a instaurar-se. ${ }^{4}$ Críticas ao Legislativo se haviam 
difundido conforme se acentuava o clima de decepção com a República, chegando até mesmo a círculos próximos à tradição liberal. Na década de 1920, O Estado de São Paulo não poupou ataques a tal poder estatal, visto como "ineficiente", "displicente" e "submisso ao Executivo" (Capelato, Prado, 1980: 29).

Essas críticas assumiriam nova roupagem em entrevista concedida por Francisco Campos à imprensa logo após o golpe do Estado Novo, publicada com destaque pela Revista Forense. Um dos argumentos empregados por Campos foi a "incapacidade do Poder Legislativo para legislar", vista como "um dado definitivamente adquirido não só pela ciência política como pela experiência das instituições representativas". Dadas as feições amplas e intervencionistas que o Estado havia assumido, a atividade legislativa perdera "seu caráter exclusivamente político", para se tornar "uma técnica que exige o concurso de vários conhecimentos e de várias técnicas" (Campos, 1938: 9-13).

Para além do empenho em legitimar o regime, é interessante perceber os laços da fala de Campos com debates em curso na teoria jurídica. Na França, Redor (1995: 89-96) mostrou como juristas passaram, na virada do século XIX ao XX, a enxergar o Legislativo como uma instituição que estaria, desde o estabelecimento do sufrágio universal, levando o país à beira da guerra social e do "despotismo democrático". Contrapunham ao falho parlamento uma visão idealizada do direito, fundada em duas crenças básicas: a de que as garantias jurídicas eram mais eficazes que as políticas e a ideia de "excelência" do direito, tomado como um "verdadeiro soberano" que se impunha ao Estado. Consolidou-se, assim, uma descrição do "campo político como um mundo de conflitos, uma espécie de estado de natureza caótico". Ao direito, em contrapartida, seriam atribuídas todas as virtudes, afirmando-o como um "lugar pretensamente neutro de resolução dos conflitos pelo recurso à lógica interna de uma ordem jurídica coerente" (Redor, 1995: 89-96).

Essas propostas ganharam concretude institucional com a Société d'Études Législatives. Criada em Paris em 1901, essa organização reuniu juristas preocupados em influir sobre os rumos das atividades do parlamento e impulsionar reformas nas leis (Société..., 1902: 5). Na fala com que abrimos este texto, qualificada como "magistral discurso" na transcrição feita pela Revista Forense, Francisco Campos propôs uma "organização racional do serviço legislativo". Para tanto, deveria ser criado "um centro de estudos, de informações e de investigações com a função de verificar as lacunas e defeitos do sistema jurídico, os vícios do seu funcionamento ou as inadequações ou incompatibilidades do direito" com a vida social (Congresso..., 1936: 809-810). Embora o futuro Ministro da Justiça não faça menções à iniciativa francesa, há aproximações quanto à defesa de um projeto elitista de sociedade, em que se atribuía um papel de protagonismo aos detentores do conhecimento "técnico". 
Em outubro de 1937, o antecessor de Campos em tal pasta, José Carlos de Macedo Soares, apresentou ao governo uma proposta de criação de uma Comissão de Estudo para o Progresso do Direito, também reproduzida pela Forense. De maneira muito semelhante ao que fizera Campos, Macedo Soares (1937: 202-203) partiu da constatação de que os "dogmas científicos" do século XIX "ruíram como castelos de cartas" para afirmar a necessidade de 0 direito "acompanhar, constantemente, o progresso dos conhecimentos para manter contato com a vida que pretende reger". Para tanto, seria necessário "pôr a serviço do Estado um órgão plástico, sensível, de receptividade profunda e geral que registre, selecione, aproveite as conquistas do progresso humano em todos os setores do pensamento e da ação". Tal órgão tornaria possível incorporar ao direito "as conquistas da técnica de modo que nada lhe escape na realidade social" . A sua composição, "de juristas especializados", mas comportando também "homens de reconhecido espírito público e técnicos adequados às suas consultas", permitiria que a Comissão desse "ao ministério da justiça as antenas que lhe faltam, para colher, na complexidade da vida nacional, as vibrações da ânsia de justiça que existe no fundo do coração humano".

A ruptura política operada pouco após a apresentação da proposta possivelmente obstou a concretização do órgão. Ainda em dezembro de 1930, entretanto, Vargas procurara dotar seu governo provisório de um mecanismo para a elaboração das leis, com traços bastante distintos dos de um parlamento tradicional. Composta por "juristas de reconhecido saber e reputação" ou "outros técnicos que tenham os mesmos merecimentos", a Comissão Legislativa deveria promover reformas nas mais variadas especialidades do direito. Vargas preocupou-se igualmente em garantir uma discussão prévia à promulgação com força de lei, determinando que os projetos fossem publicados para que sofressem "críticas e observações" (Brasil, 1930). As atividades da Comissão encontraram resistências nos meios jurídicos (Comissão..., 1932: CXLIX-CL) e certamente foram afetadas pela eclosão do movimento constitucionalista. Algumas dessas normas, entretanto, foram promulgadas ainda antes que se reunisse a Constituinte, como o Código Eleitoral (1932).

Muitas outras leis seriam concretizadas durante o período em que Francisco Campos esteve à frente do Ministério da Justiça. Os projetos elaborados sob seu comando foram encomendados a juristas de renome, quase sempre professores universitários, alguns deles pouco simpáticos ao governo. Foi o caso de Alcântara Machado, catedrático da Faculdade de Direito de São Paulo, ligado às oligarquias desse estado e envolvido no levante de 1932, que apresentou em 1938 um projeto de Código Penal, transformado em lei em 1940. Houve também uma preocupação em promover debates públicos, ainda que com limites. Os textos finais eram acompanhados de exposições de motivos, em que Campos buscava justificar as 
escolhas e orientações teóricas adotadas, em diálogo com a intenção de atribuir uma dimensão intelectual à escrita das leis.

\section{O DIREITO COMO CIÊNCIA EXPERIMENTAL: EM BUSCA DA SUPERAÇÃO DO "BACHARELISMO"}

preocupação em fundar espaços institucionais para promover um estudo sistemático
do direito, o recurso a "especialistas" para a escrita das leis e a redação de textos voltados para a apresentação acadêmica das novas normas podem ser vistos como expressões da percepção de que a "objetividade do método sociológico estaria invadindo cada vez mais o campo dos estudos jurídicos" (Bresciani, 2007: 319). Ao contrário de seus colegas do século anterior, os juristas brasileiros das décadas de 1930 e 1940 procuraram transitar por outros domínios do saber, menos em busca de uma erudição herdeira dos ideais humanistas da llustração que como uma tentativa de superar as limitações de que eram acusados.

Mais do que isso, essa busca por construir uma "moderna ciência do direito", fundada em métodos "objetivos", deve ser entendida a partir de uma relação tensa com a perda de jurisdição sobre parte do conhecimento acerca do social que a emergência de cursos especializados em humanidades representa. Outro paralelo pode ser traçado com o caso francês. Discutindo a situação das universidades da França na passagem do século XIX para o XX, Audren (2011: 13-18) ressaltou como, diante da institucionalização da sociologia, os professores de direito se esforçaram para manter sua posição de proeminência, fazendo da ideia de que "o direito era a ciência social por excelência" uma arma de combate. Ao mesmo tempo, esses "saberes sociais concorrentes" foram ganhando espaço dentro da formação jurídica, numa tentativa de revigorá-la e "atualizá-la", em face das necessidades de uma sociedade que era vista como cada vez mais complexa.

0 segundo desses traços pode ser percebido na reforma que buscou, em abril de 1931, "modernizar" o ensino superior brasileiro, fundando-o em bases "técnicas" e "científicas" (Abreu, 2001). Francisco Campos ocupava o Ministério da Educação e Saúde Pública nesse momento, e foi o responsável pela justificação das mudanças introduzidas. Quanto ao ensino jurídico, destacou a divisão entre os cursos de bacharelado, voltado para a "formação de práticos do direito", e de doutorado, dedicado à "alta cultura jurídica". Sobre o primeiro deles, enfatizou a substituição da cadeira de filosofia do direito pela de introdução à ciência do direito como sinal da busca por dotar o ensino jurídico de um caráter sistêmico. Isso seria reforçado pelo deslocamento do curso de economia política para o primeiro ano, por serem as relações econômicas "um pressuposto necessário do fato jurídico" (Campos, 1931: 401-402). 
A contrapartida das tentativas de construir um novo direito "técnico" reside, portanto, na preocupação em o aproximar de uma "ciência objetiva", em alguns momentos vista até mesmo como "experimental". Discursando na sessão comemorativa dos 50 anos da FND, em outubro de 1941, San Tiago Dantas ${ }^{5}$ desenvolveu o tema de maneira reveladora. Indagando-se sobre os rumos da disciplina a que se dedicava, disse ele:

o jurista, nos estudos que empreende sobre a nova ordem legal, está fazendo um trabalho ao mesmo tempo de experimentação e de integração da obra do legislador. Ele experimenta cientificamente as normas, quando as envolve no tecido das suas induções e deduções; do seu trabalho resulta, portanto, uma verificação da Política, a qual já sabemos que se legitima graças ao Direito que se mostra capaz de engendrar. E ele, jurista, ainda integra a obra legislativa, quando dela extrai os princípios, as analogias, que depois vão passar, por obra dos juízes, ao corpo do Direito positivo (Dantas, 1942a: 120). ${ }^{6}$

\section{O DIAGNÓSTICO DA FALÊNCIA DO LIBERALISMO E A "SOCIALIZAÇÃO DO DiREITO"}

E ssa defesa da complementariedade entre juristas e poderes públicos mostra como é preciso ir além da pretensa neutralidade que se buscava construir para encontrar os significados políticos dos debates que temos acompanhado. 0 antiparlamentarismo e as tentativas de atingir um direito "técnico", fundado em um conhecimento objetivo da "realidade social", convergiram em um sentido específico. Uma conferência proferida em São Paulo em agosto de 1940 por Pedro Batista Martins permite entrever essa confluência.

Advogado próximo a Francisco Campos, Martins já era reconhecido como autor do projeto que dera origem ao Código de Processo Civil, promulgado no ano anterior. Publicada na Revista Forense com o título "Getúlio Vargas e a renovação do direito nacional", a fala se abriu com a constatação da "perplexidade" dos juristas "ante o desmoronamento" de categorias que eles se haviam habituado a "tratar como definitivas", "geradas à sombra do individualismo político e do liberalismo econômico". Martins (1940: 259) logo se preocupou em criticar os partidários do "espírito do passado", incapazes de conceber "o direito como expressão de circunstâncias econômicas, políticas e sociais".

Essa fala expõe as conexões entre a busca por uma "ciência positiva" do direito e o antiliberalismo. Em um quadro internacional de ataques e revisões ao ideário liberal, potencializados pela depressão econômica iniciada em 1929, difundiu-se um sentimento de crise, diante da impressão de que o clima de crença incontida no progresso vivido durante a Belle 
Époque se desfazia. Esse sentimento de crise foi "objeto de forte investimento político-ideológico" no Brasil dos anos 1930, participando da fabricação de um clima de temor do caos e da desagregação social amplamente manipulado politicamente, à esquerda como à direita, a partir de temas nacionalistas e patrióticos, vistos como hábeis para afastar esse "perigo" e promover a "salvação nacional" (Dutra, 2012: 140-142).

0 desenvolvimento dessas ideias foi favorecido pelo processo de contestação em que mergulhara a Primeira República, sinalizado pelo incremento dos conflitos e dos movimentos sociais, com fortes greves na passagem da década de 1910 à de 1920, aliadas em 1922 à emergência do tenentismo, à Semana de Arte Moderna, à fundação do Partido Comunista. As efemérides do centenário da Independência (1922) e dos 35 anos da República (1924) impulsionaram esforços para "repensar o Brasil", dando voz à crescente decepção com as "promessas não cumpridas" do regime instaurado em 1889. A Constituição de 1891 foi frequentemente censurada, acusada de ser "idealista" e "inadequada à realidade nacional".

No âmbito da teoria jurídica, uma preocupação abstrata com "o social" buscou trazer respostas a esses desafios, sendo capaz de congregar e mobilizar bacharéis em direito de orientações diversas. Procurando, a um só tempo, apontar alternativas ao liberalismo clássico e evitar as transformações profundas pleiteadas à esquerda do espectro político, muitos juristas se puseram a reivindicar uma "concepção social do direito" . Embora tenha comportado variações importantes, alguns dos conteúdos atribuídos a esse projeto foram a defesa da prevalência dos interesses coletivos sobre os individuais, a busca por um maior intervencionismo estatal, propostas sobre a relativização de direitos antes tidos como absolutos (em especial, a liberdade de contratar e a propriedade), a crítica à "importação" de modelos estrangeiros, a busca por uma correlação entre lei e realidade social e 0 intuito de promover reformas sociais por meio das leis.

Outra passagem da conferência de Martins (1940: 260) deixa claro como a "socialização do direito" foi o principal sentido que se procurou atribuir às mudanças nas leis empreendidas pelo governo Vargas: "Todas as reformas legislativas do presidente Vargas têm obedecido a um só sistema e objetivado o mesmo fim, que é a socialização do direito, o qual se vai tornando mais amplo e compreensivo, porque vai envolvendo, na sua tutela, o interesse do pobre e do rico, do salariado e do proprietário, do homem e da mulher, sem admitir as excomunhões tão frequentes no direito anterior."

É, portanto, nessa articulação complexa entre convicções intelectuais e um projeto de transformação da realidade a partir de inovações legislativas que se percebe o pleno significado da busca, entre os juristas, pelo estudo do social. A visão de que era possível alcançar um conhecimento "objetivo" era tomada como requisito e chave para reformar o universo jurídico, ao passo que a busca por leis "adequadas" à "realidade nacional" permeava os esforços 
de interpretação do Brasil. Encampado em chave autoritária pelo governo Vargas, esse projeto legou, na letra da lei, efeitos extremamente duradouros.

\section{JURISTAS E POLÍTICA EM TEMPOS DE}

\section{ANTILIBERALISMO: UM BALANÇO}

E m dezembro de 1937, Bilac Pinto redigiu uma carta em que se recusava a atender ao pedido de Pedro Aleixo para ser readmitido no corpo editorial da Revista Forense. Aleixo se havia afastado da redação ao assumir a presidência da Câmara dos Deputados, em maio daquele ano. Deposto pelo golpe do Estado Novo, o político mineiro enviou, ainda em 10 de novembro de 1937, um telegrama a Vargas em que protestava contra a medida. ${ }^{8}$ No dia seguinte, Aleixo dirigiria uma manifestação mais contundente ao interventor de seu estado, Benedito Valadares. ${ }^{9}$

Em sua carta, Bilac Pinto ressaltou que "os principais clientes" da Forense eram "os governos". Mais à frente, foi explícito quanto à inconveniência do retorno daquele que havia sido seu parceiro na transferência do periódico para o Rio de Janeiro, afirmando: "dependendo a Revista, decisivamente, da boa vontade dos atuais detentores do poder, receio que o nome do único e grande dissidente do Estado Novo, figurando na direção da Revista, traga para ela dificuldades, mormente nesta fase de estabelecimento de contato com a nova situação". ${ }^{10}$

Seria tentador, diante dessa argumentação, bem como da presença de membros da redação da Forense em cargos estatais, ${ }^{11}$ enveredar por explicações que atribuem a mecanismos de "cooptação" a proximidade entre ideias defendidas em tal revista e debates veiculados em Cultura Política. Mostramos, porém, como havia entre juristas e governo alguns horizontes partilhados, sobretudo quanto às reivindicações em torno da "socialização do direito" e aos intuitos de reformar as leis.

Conforme o Estado Novo perdurou, contudo, essas relações se tornaram cada vez mais difíceis. A própria "concepção social do direito" passou a sofrer censuras e revisões. Apadrinhando os formandos de 1940 da FND, um ano antes que Vargas desempenhasse o mesmo papel, Haroldo Valladão (1943: 30-31) aludiu a seu engajamento contra o "tradicionalismo jurídico" e em favor da "socialização do direito" quando ocupara a tribuna como orador de sua turma. Logo se preocupou, porém, em tecer críticas aos resultados que essas reivindicações haviam alcançado:

De um tradicionalismo enquistado passou-se a um reformismo sem orientação e sem limites, e dos abusos do individualismo caminhou a ciência jurídica para os exageros do estatismo. 
Pediu-se e se obteve que o interesse de cada um se submetesse ao da sociedade, mas depois ultrapassou-se a meta e chegou-se à absorção completa do indivíduo pelo Estado. Por tudo isto os juristas de 1940 se encontram numa atitude paradoxalmente aproximada daquela de 1921, na necessidade de pregar outra reforma jurídica, de aparar agora os excessos de um estatismo absorvente.

Alçado à presidência do IAB em abril de 1944, Valladão se empenharia no combate ao regime (Mattos, 2011: 47).

No ano anterior, havia ficado claro que qualquer respaldo de que o Estado Novo ainda pudesse desfrutar entre os juristas se desfazia rapidamente. O Congresso Jurídico Nacional, realizado em agosto de 1943, pode ser visto como um marco das mobilizações civis em favor da queda de Vargas. Em protesto contra interferências do governo nos debates, algumas delegações se retiraram do evento (Mattos, 2011: 45-46; Guimarães, Bessone, 2003: 114-115). No mês seguinte, os juristas que compunham essas delegações promoveram um almoço em homenagem a Pedro Aleixo, pensado como um ato de protesto. Quando a palavra foi dada a Aleixo, ele teceu reivindicações sobre o restabelecimento de direitos como forma de retorno à democracia. Buscou sintetizá-las afirmando: "todos os direitos se resumem em um só, o direito do homem ser livre, civicamente livre, economicamente livre". 12

A redação do Manifesto dos Mineiros, divulgado em outubro do mesmo ano e considerado uma "certidão de nascimento da oposição liberal ao Estado Novo" (Mattos, 2011: 45), deu-se como um desdobramento dessas mobilizações. Inúmeros juristas assinaram o documento, entre eles Pedro Aleixo, Bilac Pinto e Pedro Batista Martins (antes um enfático defensor das inovações legislativas do governo Vargas e do projeto de "socialização do direito"). A partir de 1944, o Conselho Federal da OAB passou a combater com empenho o Estado Novo (Mattos, 2011: 41-75).

Lidas em conjunto, essas manifestações de hostilidade ao governo apontam para uma revalorização do ideário liberal nos meios jurídicos. Favorecido no âmbito externo pela guerra e por uma mobilização crescente contra o nazi-fascismo e, no âmbito interno, por resistências à inflexão que direcionou as políticas estatais mais claramente para os trabalhadores (Gomes, 2005), esse movimento parece ter afetado até mesmo os rumos das reformas legislativas. 0 direito civil, âmbito da regulação das relações privadas por excelência, foi um dos poucos domínios em que o governo Vargas falhou em concretizar novas codificações.

Esse deslocamento pode ser associado a um movimento geral dos setores liberais, que, em face do que percebiam como "ameaças" do "caos", da "desagregação social", da "subversão comunista", não se opuseram em um primeiro momento à instauração do Estado Novo, ou mesmo a apoiaram (Capelato, 1989; Dutra, 2012; Motta, 2002). Explicita-se, assim, 
a necessidade de adensar a compreensão das relações entre juristas e liberalismo, ${ }^{13}$ sobretudo na busca por esclarecer a participação desses homens em processos de legitimação de regimes antidemocráticos. No mesmo sentido, é interessante perceber como certo movimento - se não de apoio, ao menos de ausência de um enfrentamento enérgico do autoritarismo, para desembocar, a partir de um ponto, em censuras ao regime fundadas na defesa dos direitos fundamentais e da "ordem jurídica" - pode ser identificado em muitos juristas tanto no Estado Novo quanto na Ditadura Militar ${ }^{14}$.

Não se deve esquecer, de toda maneira, que em momento algum os bacharéis empenhados no combate ao varguismo abriram mão das representações de si próprios como uma "elite esclarecida" a quem incumbia conduzir os rumos do país (Mattos, 2011: 64, 73) - ideal que os aproximava do papel atribuído aos intelectuais na política cultural do Estado Novo. Por outro lado, mais que um declínio da presença dos juristas na cena pública, o que talvez tenha ocorrido foi uma transformação de seu papel, a partir da busca por substituir o "bacharel polígrafo pluripotente" do século XIX pela figura, tida como mais "moderna", do "técnico da legalidade". Nenhum desses tipos logrou sobrepor-se por completo ao outro, e o embate entre eles tem gerado diferentes correlações de força que seria interessante explorar ao longo do tempo.

Esperamos ter trazido à tona, por fim, a importância de problematizar as reivindicações em favor de uma "técnica" salvadora, capaz de suplantar os supostos "males" da política. Deixar de fazê-lo nos expõe ao risco de reproduzir em termos analíticos argumentos mobilizados no interior dos debates do período estudado, com sentidos e objetivos específicos. Em lugar de visões normativas sobre o papel dos intelectuais e da autonomia do conhecimento, talvez seja mais produtivo investir na análise das complexas interações entre os "homens do pensamento", a sociedade em que estão inseridos e os poderes constituídos. Numa conjuntura em que temas como processo penal e direito financeiro, tidos como "técnicos" e "espinhosos" para o público em geral (e mesmo para juristas especializados em outras áreas), invadem a arena pública e alcançam efeitos políticos de grande porte, essa reflexão se faz - mais que necessária - premente.

\section{NotAS}

1 Por exemplo, Lessa (2000: 303-352).

2 Fogem ao escopo deste artigo os aspectos relativos ao exercício profissional. Os juristas aqui contemplados constituíam uma reduzida elite, reconhecida nos meios acadêmicos e institucionais, e que atribuía a si própria a "missão" de conduzir a vida pública, em certa continuidade com os "bacharéis-políticos" do século XIX. 
Sobre a regulação profissional e a estratificação social dos bacharéis em direito, ver Bonelli (2002), Coelho (1999) e Mattos (2011).

$3 \mathrm{Na}$ juventude, Tenório defendera ideias mais próximas da esquerda, tendo atuado em projetos latino-americanistas e publicado um livro sobre o México revolucionário (1928). Já sustentava, porém, posições favoráveis ao intervencionismo estatal (Streich, 2015: 63-75).

40 Poder Legislativo seria "exercido pelo Parlamento Nacional", reunido por quatro meses a cada ano, "com a colaboração do Conselho da Economia Nacional e do Presidente da República" (arts. 38 e 39). A iniciativa dos projetos de lei caberia, "em princípio, ao Governo" (art. 64). A suposta exceção do art. 180, que atribuía poderes legislativos à Presidência enquanto não se organizasse o parlamento, seria a regra durante todo 0 regime (Brasil, 1937). Em Cultura Política, contudo, as previsões sobre o Legislativo foram empregadas para afirmar a natureza democrática do governo.

5 Sua trajetória é ilustrativa da complexidade da atuação dos juristas na conjuntura aqui analisada. No início dos anos 1930, San Tiago ocupou cargo no gabinete de Francisco Campos no Ministério da Educação e Saúde. Participou do movimento integralista. Após abandonar a AIB, ingressou como docente na FND em 1940, e teve posicionamentos simpáticos ao Estado Novo. Em março de 1945, entretanto, redigiu um manifesto denunciando a ilegitimidade da Constituição de 1937 e exigindo a entrega da chefia da nação ao presidente do STF (Abreu, 2001).

60 texto fora parcialmente publicado, alguns meses antes, pela Revista Forense (Dantas, 1942b: 299-302).

7 Essa foi, para Kennedy (2006: 22 e 37), a segunda das "três globalizações do direito e do pensamento jurídico", situada entre 1900 e 1968 e definida por uma vaga noção do "Social", que "poderia ser socialista ou socialdemocrata ou Católico ou Social-Cristão ou fascista (mas não comunista ou liberal clássico)". Esse termo funcionou, assim, como um slogan, cumprindo um papel análogo ao que as ideias de vontade e de direitos individuais desempenharam no "pensamento jurídico clássico", de corte liberal e prevalecente por volta de 1850 a 1914. No Brasil, Garcia Neto (2010: 225) buscou situar a obrigação de interpretar as leis segundo suas finalidades sociais instituída pela Lei de Introdução ao Código Civil (1942) e a Consolidação das Leis do Trabalho (1943) em uma mesma busca por um "projeto jurídico condizente com o novo contexto".

8 CPDOC-FGV, LC C 1937.11.10.

9 Arquivo Público Mineiro, PA: 3.1, Cx. 01, Pc: 01.

10 Arquivo Público Mineiro, PA: 2, Cx. 01, Pc: 01. Grifos no original.

11 Para nos atermos a um caso revelador: o redator-chefe Carlos Medeiros Silva foi, nos anos 1930, chefe de gabinete de Francisco Campos na Secretaria da Educação do Distrito Federal e seu assistente no Ministério da Justiça. Na Ditadura Militar, participou da escrita da Constituição de 1967 e de diversos Atos Institucionais. Foi nomeado ministro do STF em 1965, passando a ocupar a pasta da Justiça em 1966 (Abreu, 2001).

12 Arquivo Público Mineiro, AB-PI-Cx. 05, Doc 103.

13 Para o Brasil do século XIX: Adorno (1988). Sobre o caráter liberal da oposição da OAB ao Estado Novo: Mattos, 45-74. Para perspectivas gerais e com pretensões teóricas: Halliday, Karpik (1997).

14 Sobre a atuação dos juristas no golpe de 1964 e durante a Ditadura Militar: Curi (2008); Mattos (2011); Rollemberg (2008: 57-96); Silva (2005). 


\section{REFERÊNCIAS BIBLIOGRÁFICAS}

ABREU, Alzira Alves de et al. (coords.). Dicionário histórico-biográfico brasileiro pós-1930. Rio de Janeiro: FGV, 2001. Disponível em: www.cpdoc.fgv.br. Acesso em: 19/04/2016.

ADORNO, Sérgio. Os aprendizes do poder. Rio de Janeiro: Paz e Terra, 1988.

ALTAMIRANO, Carlos. Para un programa de historia intelectual y otros ensayos. Buenos Aires: Siglo XXI, 2005.

A ATIVIDADE Governamental. Cultura Política. Rio de Janeiro, n. 1, p. 209, mar. 1941.

AUDREN, Frédéric. L'histoire intellectuelle du droit ou la fin du "Grand Partage". Clio@Thémis. Paris, n. IX, p. 1-4, dez. 2015.

. Les professeurs de droit, la République et le nouvel esprit juridique. Mil neuf cent. Paris, n. 29, p. 7-33, 2011.

BOMENY, Helena (org.). Constelação Capanema. Rio de Janeiro: FGV, 2001.

BONELLI, Maria da Gloria. Profissionalismo e política no mundo do direito. São Carlos: EdUFSCar: Sumaré, 2002.

BRASIL. Constituição da República. Rio de Janeiro, 1937.

Decreto nº 19.459, de 6 de Dezembro de 1930. Rio de Janeiro, 1930.

BRESCIANI, Maria Stella Martins. O charme da ciência e a sedução da objetividade. São Paulo: Unesp, 2007.

CAMPOS, Francisco. Diretrizes constitucionais do novo Estado Brasileiro. Revista Forense. Rio de Janeiro, v. LXXIII, n. 415, p. 5-22, jan. 1938.

. A reforma do ensino superior no Brasil. Revista Forense. Rio de Janeiro, v. LVI, jan-jun. 1931, p. 393-415.

CAPELATO, Maria Helena. Os arautos do liberalismo. São Paulo: Brasiliense, 1989.

; PRADO, Maria Lígia. O Bravo Matutino. São Paulo: Alfa-Ômega, 1980.

CARVALHO, Menelick de. Serviços de utilidade pública. Cultura Política. Rio de Janeiro, n. 9, p. 70-89, nov. 1941.

. Serviços de utilidade pública. Revista Forense. Rio de Janeiro, v. LXXXIX, n. 463, p. 305-314, jan. 1942.

COELHO, Edmundo Campos. As profissões imperiais. Rio de Janeiro: Record, 1999.

COMISSÃO Legislativa Revolucionária. Revista de Direito Comercial. Rio de Janeiro, v. 2, n. 4, p. CXLIX-CL, 4은 tri. 1932.

CONGRESSO Nacional de Direito Judiciário. Revista Forense. Rio de Janeiro, v. LXVII, n. 398, p. 809-810, ago. 1936.

CURI, Isadora Volpato. Juristas e o Regime Militar (1964-1985). Dissertação (Mestrado em História Social) Faculdade de Filosofia, Letras e Ciências Humanas, Universidade de São Paulo, São Paulo, 2008.

DANTAS, San Tiago. Discurso pela renovação do Direito. Cultura Política. Rio de Janeiro, n. 15, p. 115-121, mai. 1942a. 

$1942 b$.

Ordem jurídica e regime político. Revista Forense. Rio de Janeiro, v., LXXXIX, n. 463, p. 299-302, jan.

DUTRA, Eliana de Freitas. O ardil totalitário. Belo Horizonte: UFMG, 2012.

Rebeldes literários da República. Belo Horizonte: UFMG, 2005.

FERREIRA, Marieta de Moraes. 0 ensino de história na Faculdade Nacional de Filosofia da Universidade do Brasil. História, Ciências, Saúde. Rio de Janeiro, v. 19, n. 2, abr.-jun. 2012, p. 611-636.

FONSECA, Pedro Cezar Dutra. Gênese e precursores do desenvolvimentismo no Brasil. In: ; BASTOS, Pedro Paulo Zahluth (orgs.). A Era Vargas. São Paulo: Unesp, 2012, p. 21-49.

GARCIA NETO, Paulo Macedo. A questão social na Era Vargas entre a regulação de trabalho da CLT e os "fins sociais" da Lei de Introdução ao Código Civil. In: MOTA, Carlos Guilherme; SALINAS, Natasha S. C. Os juristas na formação do Estado-Nação brasileiro. São Paulo: Saraiva, 2010, v. 3, p. 223-253.

GOMES, Angela de Castro. História e historiadores. Rio de Janeiro: Fundação Getúlio Vargas, 1996. A invenção do trabalhismo. Rio de Janeiro: FGV, 2005.

Novas elites burocráticas. In: (coord.); DIAS, José Luciano de Mattos; MOTTA, Marly da Silva. Engenheiros e economistas. Rio de Janeiro: FGV, 1994, p. 1-12.

GRAFTON, Anthony. The history of ideas: precept and practice, 1950-2000. Journal for the History of Ideas. Philadelphia, v. 76, n. 1, p. 1-32, jan. 2006.

GUIMARÃES, Lúcia Maria Paschoal; BESSONE, Tânia Maria Tavares. História da Ordem dos Advogados do Brasil. Brasília: OAB, 2003, v. 4.

HALLIDAY, Terence C.; KARPIK, Lucien (eds.). Lawyers and the rise of western political liberalism. New York: Oxford University Press, 1997.

KENNEDY, Duncan. Three Globalizations of Law and Legal Thought: 1850-2000. In: TRUBEK, David; SANTOS, Álvaro (eds.). The New Law and Economic Development. New York: Cambridge University Press, 2006, p. 19-73.

LESSA, Carlos. A preeminência profissional e o Estado brasileiro: dos juristas aos economistas. In: PRIORE, Mary del (org.). Revisão do Paraíso. Rio de Janeiro: Campus, 2000, p. 303-352.

LIMA, Raul. Cultura Política. Revista Forense. Rio de Janeiro, v. LXXXVI, n. 455, p. 500, mai. 1941.

LUCA, Tania Regina de. A Revista do Brasil. São Paulo: Unesp, 1999.

MARTINS, Pedro Batista. Getúlio Vargas e a Renovação do Direito Nacional. Revista Forense. Rio de Janeiro, v. LXXXIV, n. 449, p. 259-269, nov. 1940.

MATTOS, Marco Aurélio Vannucchi Leme de. Os cruzados da ordem jurídica. Tese (Doutorado em História Social) - Faculdade de Filosofia, Letras e Ciências Humanas, Universidade de São Paulo, São Paulo, 2011.

MICELI, Sergio. Intelectuais e classe dirigente no Brasil (1920-1945). São Paulo: Difel, 1979.

MOTTA, Rodrigo Patto Sá. Em guarda contra o "perigo vermelho". São Paulo: Perspectiva, 2002.

OLIVEIRA, Lúcia Lippi de. As ciências sociais no Rio de Janeiro. In: MICELI, Sergio (org.). História das ciências Sociais. São Paulo: Sumaré, 1995, v. 2, p. 233-307. 
PÉCAUT, Daniel. Os intelectuais e a política no Brasil. São Paulo: Ática, 1990.

REDOR, Marie-Joëlle. "C'est la faute à Rousseau". Les juristes contre les parlementaires sous la Ille République. Politix. v. 8, no 32, p. 89-96, 4 tri. 1995.

ROLLEMBERG, Denise. Memória, opinião e cultura política. A Ordem dos Advogados do Brasil sob a Ditadura (1964-1974). In: REIS, Daniel Aarão; ROLLAND, Denis (orgs.). Modernidades alternativas. Rio de Janeiro: FGV, 2008, p. 57-96.

SANTOS, Wanderley Guilherme dos. Roteiro bibliográfico do pensamento político-social brasileiro (18701965). Belo Horizonte: UFMG; Rio de Janeiro: Casa de Oswaldo Cruz, 2002.

SILVA, Márcia Pereira da. A defesa legal do arbítrio. Tese (Doutorado em História) - Belo Horizonte, Faculdade de Filosofia e Ciências Humanas, Universidade Federal de Minas Gerais, 2005.

SOARES, José Carlos de Macedo. Comissão de Estudo para o Progresso do Direito. Revista Forense. Rio de Janeiro, v. LXXII, n. 412, p. 202-203, out. 1937.

SOCIÉTÉ d'Études Législatives - Statuts. Bulletin de la Société d'Études Législatives. Paris, v. I, p. 5-10, 1902.

STREICH, Ricardo Neves. Interpretações da Revolução Mexicana. Dissertação (Mestrado em História Social) Faculdade de Filosofia, Letras e Ciências Humanas, Universidade de São Paulo, São Paulo, 2015.

TENÓRIO, Oscar. A elaboração das leis no Estado Moderno. Cultura Política. Rio de Janeiro, n. 8, p. 101-108, out. 1941.

VALLADÃO, Haroldo. Direito, solidariedade, justiça. Rio de Janeiro: José Olympio, 1943.

VARGAS, Getúlio. 0 novo espírito da Constituição e do Direito Brasileiros. Cultura Política. Rio de Janeiro, n. 11, p. 7-10, jan. 1942.

VELLOSO, Mônica Pimenta. Uma configuração do campo intelectual. In: ; OLIVEIRA, Lúcia Lippi; GOMES, Ângela Maria de Castro. Estado Novo Ideologia e poder. Rio de Janeiro: Zahar, 1982, p. 71-108.

. Os intelectuais e a política cultural do Estado Novo. In: FERREIRA, Jorge; DELGADO, Lucília de Almeida Neves (orgs.). O Brasil republicano. Rio de Janeiro: Civilização Brasileira, 2011, v. 2, p. 145-179.

VENANCIO FILHO, Alberto. Das arcadas ao bacharelismo. São Paulo: Perspectiva, 2004. 